\title{
Synthesis and Catalytic Applications of Ruthenium(0) Nanoparticles in Click Chemistry
}

\author{
Avvaru Praveen Kumar, Min-Wook Baek, Chirumarry Sridhar, Begari Prem Kumar, and Yong-Ill Lee \\ Department of Chemistry, Changwon National University, Changwon 641-773, Korea. *E-mail: yilee@changwon.ac.kr \\ Received November 19, 2013, Accepted December 26, 2013
}

\begin{abstract}
Here we report a facile synthesis of ruthenium $(\mathrm{Ru})$ Nanoparticles (NPs) by chemical co-precipitation method. The calcination of ruthenium hydroxide samples at $500{ }^{\circ} \mathrm{C}$ under hydrogen atmosphere lead to the formation of $\mathrm{Ru}^{0} \mathrm{NPs}$. The size and aggregation of $\mathrm{Ru}$ NPs depends on the $\mathrm{pH}$ of the medium, and type of surfactant and its concentration. The X-ray diffraction (XRD), scanning electron microscope (SEM) and transmission electron microscope image (TEM) analyses of particles indicated the formation of $\mathrm{Ru}^{0} \mathrm{NPs}$, and have 10 to $20 \mathrm{~nm}$ sizes. As-synthesized $\mathrm{Ru}^{0} \mathrm{NPs}$ are characterized and investigated their catalytic ability in click chemistry (azidealkyne cycloaddition reactions), showing good results in terms of reactivity. Interestingly, small structural differences in triazines influence the catalytic activity of $\mathrm{Ru}^{0}$ nanocatalysts. Click chemistry has recently emerged to become one of the most powerful tools in drug discovery, chemical biology, proteomics, medical sciences and nanotechnology/nanomedicine. In addition, preliminary tests of recycling showed good results with neither loss of activity or significant precipitation.
\end{abstract}

Key Words : $\mathrm{Ru}^{0}$ Nanoparticles, Chemical co-precipitation, Catalytic activity, Click chemistry

\section{Introduction}

The physical and chemical properties of metal nanoparticles (NPs) have directed towards an important matter in current nanoscience research due to interesting applications such as catalysis, optoelectronics, bio-detectors, telecommunications, photonics and sensors. ${ }^{1,2}$ Metal NPs possess a high specific surface area to volume ratio and renewable energy which are creditworthy to their catalytic activity in various organic reactions to synthesize new molecules. The transition metal NPs raised a significant care on structural arrangement and elucidation of various applications especially in catalysis of interest ${ }^{3-5}$ because they mimic metal surface activation and catalysis at nanoscale indicating higher selectivity and efficiency. ${ }^{4}$ Role of catalysis in the development of clean chemical production with limited hazardous and toxic by-products is now well-established as an essential element of sustainable processing. ${ }^{6}$

Ruthenium $(\mathrm{Ru})$ is a rare transition metal belonging to the platinum group and shows very unique and interesting catalytic activities for different reactions. For example, ruthenium is indispensable as a homogeneous catalyst in a variety of organic reactions. ${ }^{7}$ It can easily adopt various formal oxidation states from -II to +VIII in chemical bonds, ${ }^{8}$ thus giving rise to many compounds with interesting and often unique properties. ${ }^{9}$ Despite of many synthesis methods for ruthenium dioxide $\left(\mathrm{RuO}_{2}\right) \mathrm{NPs}^{10,11}$ and stabilized $\mathrm{Ru} \mathrm{NPs}^{12,13}$ there were very few reports on synthesis of Ru NPs having zero oxidation state $\left(\mathrm{Ru}^{0}\right)$ which include solvothermal ${ }^{14}$ and hydrothermal synthesis. ${ }^{15}$

There were many reports on supported Ru catalysts. ${ }^{16-18}$ However, the catalytic activity alters with particle size, electronic state, oxidation state, metal-support etc. Intrinsically, the nature of active sites for catalytic reactions can be assessed, which may in turn allow for the rational design of catalysts for desirable reactions. Apart from supported $\mathrm{Ru}$ catalysts, free Ru NPs have an advantage like high percentage of Ru which leads to increased homogeneity of resulting NPs which lead to relatively high reactivity. The present work reports a facile, less cost effective and efficient synthesis of $\mathrm{Ru}^{0} \mathrm{NPs}$ by chemical co-precipitation method. In the literature no methods are available to synthesize $\mathrm{Ru}^{0} \mathrm{NPs}$ by chemical co-precipitation method. The co-precipitation is one of the successful techniques for synthesizing NPs having narrow particle size distribution. As-synthesized $\mathrm{Ru}^{0}$ NPs have applied as nanocatalysts for azide-alkyne cycloaddition reactions (click reactions) using different substrates and results are discussed. Click chemistry is a modular approach that uses only the most practical and reliable chemical transformations. Its applications are increasingly found in all aspects of drug discovery, ranging from lead finding through combinatorial chemistry and target-templated in situ chemistry, to proteomics and DNA research, using bioconjugation reactions. ${ }^{19-21}$

\section{Experimental}

Preparation of $\mathbf{R u}^{\mathbf{0}}$ Catalyst. All chemicals and solvents were of analytical grade and used as received without further purification. The typical synthesis of $\mathrm{Ru}^{0} \mathrm{NPs}$ as follows: $\mathrm{RuCl}_{3} \cdot \mathrm{H}_{2} \mathrm{O}$ (Aldrich-40.1\% Ru) and surfactant (sodium dodecylsulfate (SDS)/cetyltrimethylammonium bromide (CTAB)/polyethylene glycol (PEG) (Sigma-Aldrich) were mixed at different molar ratios. Subsequently, the mixture was adjusted to desired $\mathrm{pH}$ using aqueous $\mathrm{NH}_{4} \mathrm{OH}$ and the resultant solution was stirred for $2 \mathrm{~h}$. The resultant suspen- 
sion was precipitated with 2-propanol and then centrifuged at $5000 \mathrm{rpm}$ under room temperature. The obtained precipitate was washed with water and acetone several times, respectively, and then dried at $60{ }^{\circ} \mathrm{C}$ in an oven. Finally, the dried precipitate was ground and calcined at $500{ }^{\circ} \mathrm{C}$ under hydrogen gas atmosphere for $2 \mathrm{~h}$ to produce $\mathrm{Ru}^{0} \mathrm{NPs}$.

Instrumentation. Thermogravimetric and thermal differential analyses (TG-DTA) of $\mathrm{Ru}^{0} \mathrm{NP}$ samples were performed by a simultaneous SDT Q200 (USA) analyzer at a heating rate of $10{ }^{\circ} \mathrm{C} \mathrm{min}{ }^{-1}$ under nitrogen gas flow. The XRD patterns of the calcined $\mathrm{Ru}^{0} \mathrm{NPs}$ were recorded using X-ray diffraction (Philips X'pert MPD 3040) with $\mathrm{Cu} \mathrm{K \alpha}$ radiation over a $2 \theta$ range from $20^{\circ}$ to $80^{\circ}$ at $2.5^{\circ} / \mathrm{min}$. Transmission electron microscopy (JEM 2100F) was performed at an accelerating voltage of $200 \mathrm{kV}$ on a copper grid. Scanning electron microscopy (SEM) images and energy dispersive spectrometry (EDS) of the products were obtained on a field-emission scanning electron micro analyzer (FE-SEMMIRA II, LMH). ${ }^{1} \mathrm{H}-\mathrm{NMR}$ and ${ }^{13} \mathrm{C}-\mathrm{NMR}$ spectra were recorded on a Bruker Avance-400 spectrometer.

Procedure for Click Reactions. The chemicals for all click reactions were obtained from commercial suppliers and used without purification. All reactions were performed under a nitrogen atmosphere. Click reactions 1, 2 \& 3: To a solution of azide (1.09 mmol, $1 \mathrm{eq})$ and alkyne $(1.31 \mathrm{mmol}$, $1.2 \mathrm{eq})$ in THF $(10 \mathrm{~mL})$ was added $\mathrm{Ru}^{0} \mathrm{NPs}(5 \mathrm{mg})$. The reaction was flushed with nitrogen, capped and heated to 70 ${ }^{\circ} \mathrm{C}$ for $4 \mathrm{~h}$. After monitoring the reaction mixture by TLC, the $\mathrm{Ru}^{0}$ catalyst was collected through filtration wash twice with ethyl acetate $(10 \times 2)$ and reused for next reaction. Filtrate was concentrated in vacuum rotary vapor to remove organic solvents to obtained a cured compound which upon purified by column chromatography (ethyl acetate/hexane 1/ 6) to get corresponding products.

Click Reaction Product 1: ${ }^{1} \mathrm{H}-\mathrm{NMR}$ (400 MHz, $\mathrm{CDCl}_{3}$ ) $\delta 7.59(\mathrm{~s}, 1 \mathrm{H}), 4.76(\mathrm{~d}, J=7.07 \mathrm{~Hz}, 2 \mathrm{H}), 4.28-4.45(\mathrm{~m}, 2 \mathrm{H})$, 3.88-4.04 (brs, 1H), 1.8-2.00 (m, 2H), 1.17-1.46 (m, 14H), $0.87(\mathrm{t}, J=7.07 \mathrm{~Hz}, 3 \mathrm{H}) .{ }^{13} \mathrm{C}-\mathrm{NMR}\left(100 \mathrm{MHz}, \mathrm{CDCl}_{3}\right) \delta$ $136.01,121.29,59.87,49.63,31.34,28.92,28.88,28.75$, 28.58, 28.49, 25.95, 22.14, 13.59 .

Click Reaction Product 2: ${ }^{1} \mathrm{H}-\mathrm{NMR}\left(400 \mathrm{MHz}, \mathrm{CDCl}_{3}\right)$ $\delta 7.50(\mathrm{~s}, 1 \mathrm{H}), 7.33-7.39(\mathrm{~m}, 3 \mathrm{H}), 7.26-7.30(\mathrm{~m}, 2 \mathrm{H}), 5.53(\mathrm{~s}$, 2H), 4.77 (s, 2H), 3.75 (brs, 1H). ${ }^{13} \mathrm{C}-\mathrm{NMR}(100 \mathrm{MHz}$, $\left.\mathrm{CDCl}_{3}\right) \delta 134.04,129.06,128.80,128.22,127.79,122.31$, 55.80, 54.38.

Click Reaction Product 3: ${ }^{1} \mathrm{H}-\mathrm{NMR}$ (400 MHz, $\mathrm{CDCl}_{3}$ ) $\delta 7.42$ (s, 1H), 7.28-7.35 (m, 3H), 7.19-7.27 (m, 2H), 5.47 (s, $2 \mathrm{H}), 3.86(\mathrm{~s}, 2 \mathrm{H}), 3.63(\mathrm{bs}, 1 \mathrm{H}), 2.91(\mathrm{t}, J=6.06 \mathrm{~Hz}, 2 \mathrm{H})$. ${ }^{13} \mathrm{C}-\mathrm{NMR}\left(100 \mathrm{MHz}, \mathrm{CDCl}_{3}\right) \delta 134.41,128.90,128.54$, $127.95,127.66,122.29,61.14,54.05,28.75$.

Click Reactions 4 \& 5: To a solution of azide $(2.88$ mmol, 3.5 eq) and (alkyne) 2,4,6-tris(prop-2-ynyloxy)-1,3,5triazine $(0.823 \mathrm{mmol}, 1 \mathrm{eq})$ in THF $(10 \mathrm{~mL})$ was added $\mathrm{Ru}^{\circ}$ NPs $(10 \mathrm{mg})$. The reaction was flushed with nitrogen, capped and heated to $70{ }^{\circ} \mathrm{C}$ for 4 hours. After monitoring the reaction mixture by $\mathrm{TLC}$, the $\mathrm{Ru}^{0}$ catalyst was collected through filtration wash twice with ethyl acetate $(10 \times 2)$ and reused for next reaction. Filtrate was concentrated in vacuum rotary vapor to remove organic solvents to obtained a cured compound which upon purified by column chromatography.

Click Reaction Product 4: ${ }^{1} \mathrm{H}-\mathrm{NMR}\left(400 \mathrm{MHz}, \mathrm{CDCl}_{3}\right)$ $\delta 7.81(\mathrm{~s}, 3 \mathrm{H}), 5.69(\mathrm{~s}, 6 \mathrm{H}), 4.35-4.46(\mathrm{~m}, 6 \mathrm{H}), 1.8-2.07(\mathrm{~m}$, $6 \mathrm{H}), 1.15-1.43(\mathrm{~m}, 48 \mathrm{H}), 0.9(\mathrm{t}, J=7.07 \mathrm{~Hz}, 9 \mathrm{H}) .{ }^{13} \mathrm{C}-\mathrm{NMR}$ $\left(100 \mathrm{MHz} \mathrm{CDCl}_{3}\right) \delta 171.55,137.93,123.59,63.02,50.62$, $31.98,29.79$, 29.40, 29.31, 29.19, 28.90, 26.28, 20.96, 14.12 .

Click Reaction Product 5: ${ }^{1} \mathrm{H}-\mathrm{NMR}\left(400 \mathrm{MHz}, \mathrm{CDCl}_{3}\right.$ )

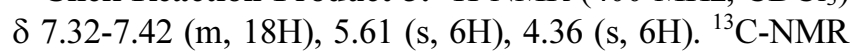
$\left(100 \mathrm{MHz}, \mathrm{CDCl}_{3}\right) \delta 172.59,135.31,129.21,128.80,128.27$, $128.17,123.01,76.85,54.76$.

\section{Results and Discussion}

Initially, the experiments were performed to prepare $\mathrm{Ru}^{0}$ $\mathrm{NPs}$ at different pHs ranging from 8 to 11 without adding surfactant. The chemical reactions involved during the formation of $\mathrm{Ru}^{0} \mathrm{NPs}$ can be represented in the following equations:

$$
\begin{aligned}
\mathrm{RuCl}_{3}+\mathrm{NH}_{4} \mathrm{OH} & \stackrel{\mathrm{pH} 8,9,10 \text { or } 11}{\longrightarrow} \mathrm{Ru}(\mathrm{OH})_{3} \downarrow+3 \mathrm{NH}_{4} \mathrm{Cl} \\
2 \mathrm{Ru}(\mathrm{OH})_{3} & \stackrel{\mathrm{H}_{2}}{600{ }^{\circ} \mathrm{C}} 2 \mathrm{RuO}_{2}+2 \mathrm{H}_{2} \mathrm{O}+\mathrm{H}_{2} \\
2 \mathrm{RuO}_{2} & \stackrel{\mathrm{H}_{2}}{600{ }^{\circ} \mathrm{C}} 2 \mathrm{Ru}+4 \mathrm{H}_{2} \mathrm{O}
\end{aligned}
$$

It has been observed the aggregation of $\mathrm{Ru}^{0} \mathrm{NPs}$ in all $\mathrm{pHs}$, and their sizes were $30 \pm 2 \mathrm{~nm}$ and $25 \pm 2 \mathrm{~nm}$ for $\mathrm{pHs} 8$ and 9, respectively, there after increased NP size to $40 \mathrm{~nm}$, and also their aggregation. It is recognizable that $\mathrm{pH}$ influences $\mathrm{Ru}^{0} \mathrm{NPs}$ size and so $\mathrm{pH} 9$ was preferred for further synthesis. The reason could be as the $\mathrm{pH}$ of the ruthenium reaction system changes from acidic to basic, $\mathrm{Ru}(\mathrm{OH})_{3}$ generates by hydrolysis of $\mathrm{Ru}^{3+}$. Subsequently, as $\mathrm{pH}$ of the reaction system increased, nucleation of $\mathrm{Ru}^{3+}$ nucleus is easier and also growth of $\mathrm{Ru}^{3+}$ nucleus is easier to happen to increase Ru NPs size and their aggregation.

In order to reduce size, aggregation and better dispersion of $\mathrm{Ru}^{0} \mathrm{NPs}$, three different types of surfactants including anionic (SDS), cationic (CTAB) and non-ionic (PEG) were tested. The anionic surfactant, SDS was found to be less aggregation and better dispersion of particles, and then PEG and $\mathrm{CTAB}$, respectively. This could be associated with different mechanisms of different kinds of surfactants. The NPs surface possesses either positive or negative charge in aqueous medium by ionization or dissociation of surface groups and they can absorb ionic surfactants. This consequence in the formation of an electrical double layer to prevent aggregation. ${ }^{22}$ Accordingly, $\mathrm{Ru}^{0} \mathrm{NPs}$ acquires positive charges in aqueous solution at basic pHs and therefore, anionic SDS surfactant can easily be absorbed on the surface of the nanoparticle precipitates and form a molecular layer on the surface of the particles to stop their aggregation. Further, the concentration effect of SDS was performed at 5 

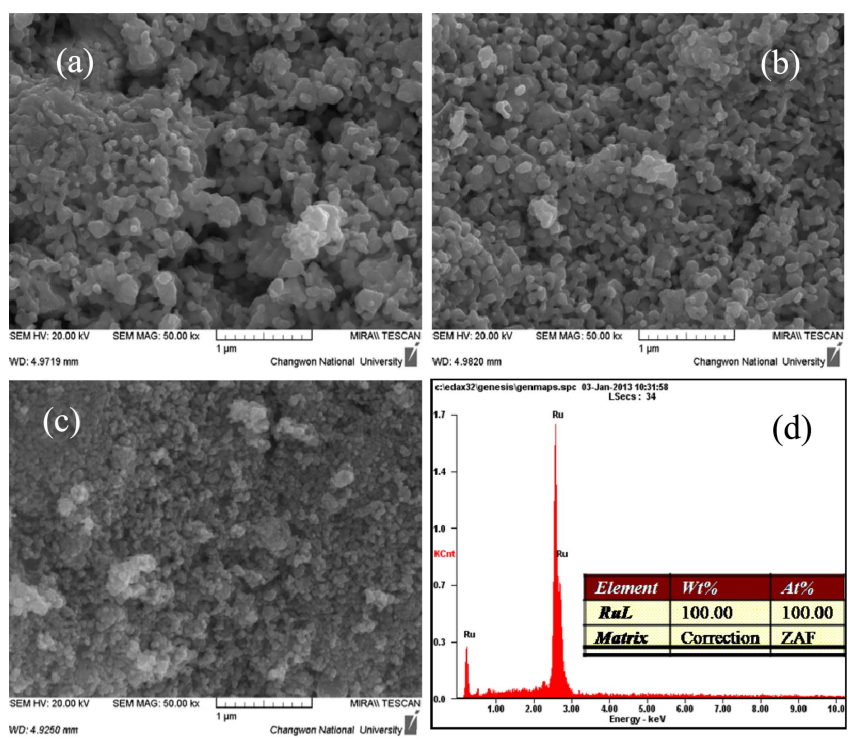

Figure 1. FE-SEM images of $\mathrm{Ru}^{0} \mathrm{NP}$ samples at $\mathrm{pH}$ 9.0: Molar ratios of [Ru]:[SDS], (a) 1:25, (b) 1.50, (c) 1:100, and (d) EDAX analysis.

different molar ratios of [Ru]:[SDS] from 1:25 to $1: 200$, so as to get better dispersion and lower particle sizes. As shown in the Figure 1, a molar ratio of 1:100 (Fig. 1(c)) was found to be low aggregation of $\mathrm{Ru}^{0} \mathrm{NPs}$ and further increase of this molar ratio resulting an increased aggregation, indicated saturated concentration of surfactant. The increased surfactant concentration gives higher viscosity which led to reduced rate of surfactant migration and decreased rate of electrostatic repulsion, thereby promoting the particle aggregation. ${ }^{23}$ The EDAX analysis of $\mathrm{Ru}^{0} \mathrm{NPs}$ was presented in Figure 1(d) and shows the existence of only $\mathrm{Ru}$ content, indicates the complete reduction of $\mathrm{Ru}(\mathrm{OH})_{3}$ to $\mathrm{RuO}_{2}$ and then to $\operatorname{Ru}(0)$.

The TEM images of $\mathrm{Ru}^{0} \mathrm{NP}$ samples were presented in Figure 2(a) and (b), and confirm the surfactant role to reduce the aggregation and better dispersion $\mathrm{Ru}^{0} \mathrm{NPs}$. TEM indicates the $\mathrm{Ru}^{0} \mathrm{NPs}$ were formed between 10 to $20 \mathrm{~nm}$ sizes. Figure 2(c) shows the selected area electron diffraction pattern (SAED) of $\mathrm{Ru}^{0} \mathrm{NPs}$. The $\mathrm{Ru}^{0} \mathrm{NPs}$ sample ([Ru]: [SDS] ratio $=1: 100)$ displays six diffused diffraction rings, assigned to the (100), (002), (101), (102), (110), and (103) reflections, respectively, corresponding to hexagonal closepacked (hcp). The effect of Ru content was also carried out by keeping the surfactant concentration constant and varying the concentration of $\mathrm{Ru}$ (three different concentrations including $0.25,0.5,1$ and $2.5 \mathrm{mM}$ ). It was observed that the increased concentration of Ru makes to increase the particle size as well as increased aggregation. So, a $0.5 \mathrm{mM}$ concentration of Ru was found to be optimum (Fig. 2(b)).

Figure 3(a) shows the TGA curve of the $\mathrm{Ru}^{0} \mathrm{NPs}$ sample before clacination. From TGA curve it has been observed that the weight loss was up to $500{ }^{\circ} \mathrm{C}$ and after that there was no significant weight loss. This weight loss is due to dehydration process wherein a significant amount of water is released from the $\mathrm{Ru}(\mathrm{OH})_{3}$ sample. Figure 3(b) presents the
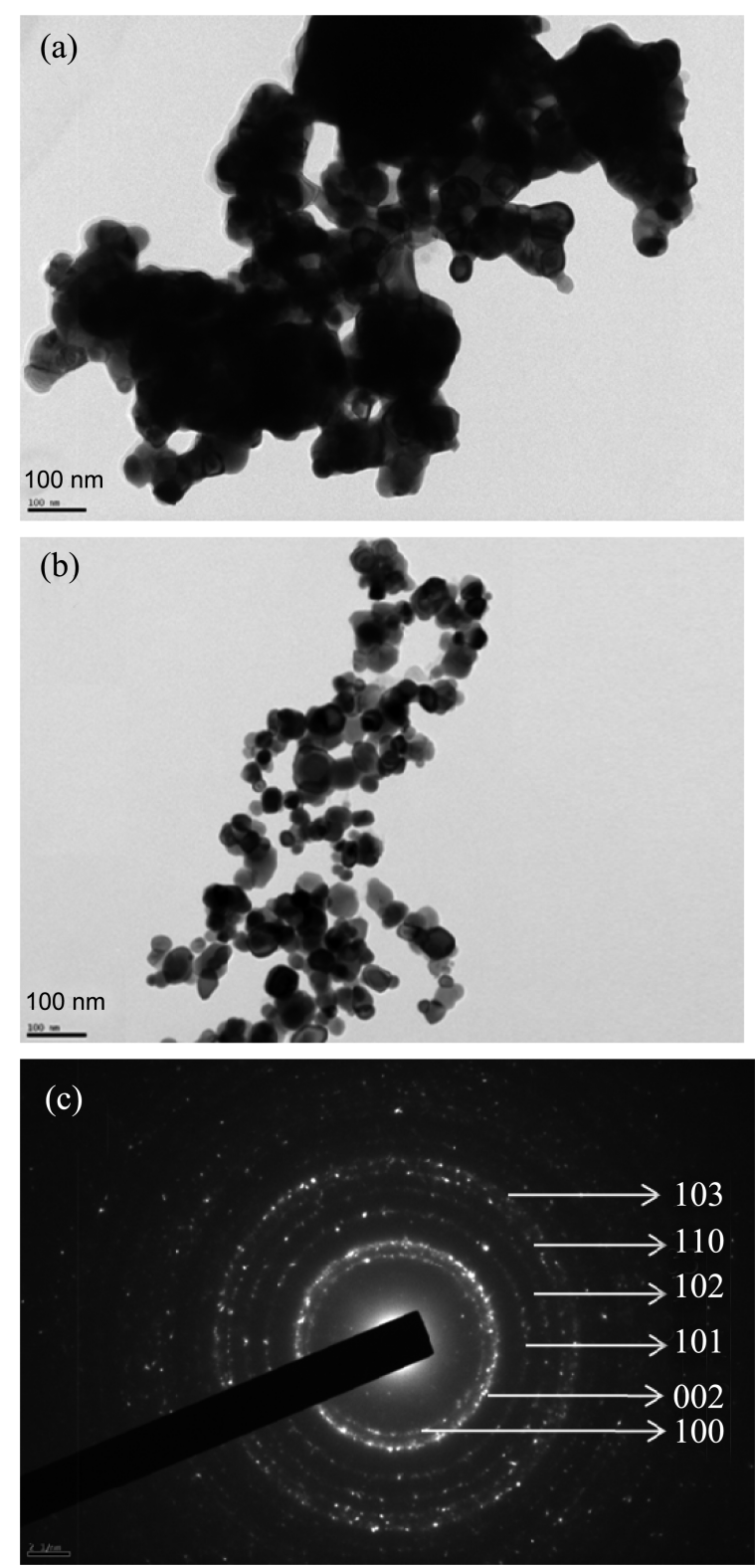

Figure 2. TEM images of $\mathrm{Ru}^{0} \mathrm{NP}$ samples at $\mathrm{pH}$ 9.0: (a) No surfactant $([\mathrm{Ru}]=0.5 \mathrm{mM})$, (b) molar ratios of $[\mathrm{Ru}]:[\mathrm{SDS}]=1: 100$, and (c) electron diffraction pattern.

XRD pattern of the $\mathrm{Ru}^{0} \mathrm{NPs}$ calcined at $500{ }^{\circ} \mathrm{C}$ which were prepared using SDS surfactant. The sharp peaks at 38.4, $42.2,44.0,58.2,69.6$, and 78.4 degree $2 \theta$ are due to the diffractions of the (100), (002), (101), (102), (110), and (103) planes of the hexagonal close-packed (hcp) Ru metal, respectively (ICDD-JCPDS card No. 06-0663). This indicates the reduction of $\mathrm{RuO}_{2}$ to $\mathrm{Ru}(0)$ during calcination in hydrogen gas atmosphere and confirms the formation of $\mathrm{Ru}^{0}$ NPs.

Click chemistry directs mainly on high degree of efficient reactions that would achieve quantitative conversion under modest conditions and necessitate only facile separations. Click reactions are ideal candidates for broad implementation and development in chemical, biological, pharmaceutical, drug development, medical and biomedical appli- 

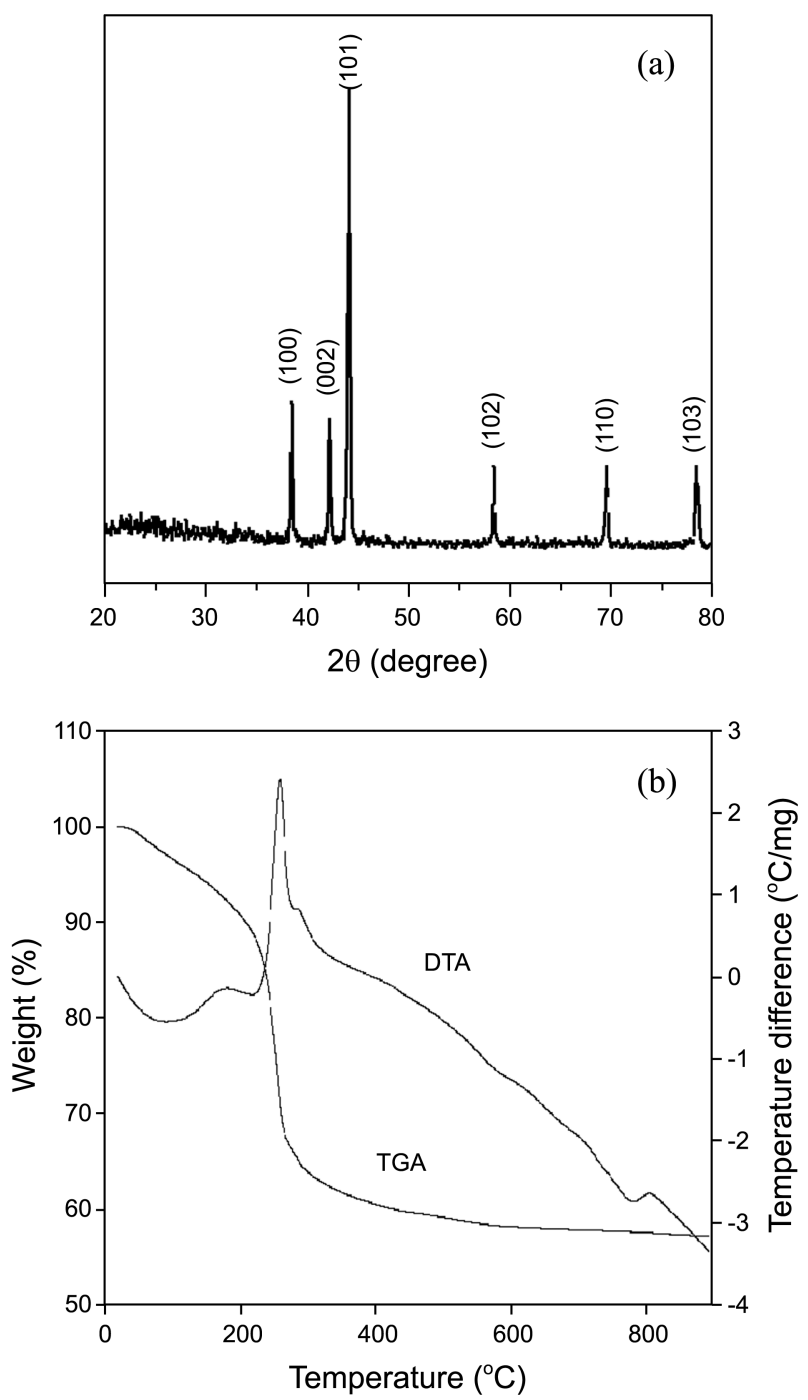

Figure 3. (a) XRD pattern and (b) TG-DTA curves of $\mathrm{Ru}^{0} \mathrm{NP}$ samples at $\mathrm{pH}$ 9.0.

cations. ${ }^{19-21,24,25}$ The $\mathrm{Cu}(\mathrm{I})$-catalyzed azide-alkyne cycloaddition reactions (click reactions) ${ }^{26,27}$ have enabled discovery of novel bioactive compounds and ligands for transition metals, new materials, and bioconjugates, emphasizing its wide range and fidelity. ${ }^{28,29} \mathrm{Apart}$ from $\mathrm{Cu}(\mathrm{I})$, Ru-catalyzed azide-alkyne cycloaddition reactions have received considerable attention during recent years. ${ }^{30,31,32}$ Keeping in mind the broad scope of transformations of alkynes catalyzed by ruthenium species, the catalytic activity of as-synthesized $\mathrm{Ru}^{0} \mathrm{NPs}$ in azide-alkyne cycloadditions has been evaluated for the synthesis of 1,2,3-triazoles.

In this work, we synthesized mono-triazoles and tri-triazoles in one molecule. Mono-triazoles were synthesized by considering propyne-1-ol and butyne-1-ol as alkynes and 1azidodecane and benzyl azide as azides (Table 1). The obtained products were characterized by ${ }^{1} \mathrm{H}-\mathrm{NMR}$ and ${ }^{13} \mathrm{C}$ NMR to confirm the structures 1,2 and 3. ${ }^{1} \mathrm{H}-\mathrm{NMR}$ of compound 1 peaks at $\delta 7.59(\mathrm{~s}, 1 \mathrm{H})$ indicates the presence of olefinic proton of triazole ring, $\delta 4.76(\mathrm{~d}, J=7.07 \mathrm{~Hz}, 2 \mathrm{H})$ indicates the presence of $-\mathrm{CH}_{2}-\mathrm{OH}$, and the peak at 4.28-

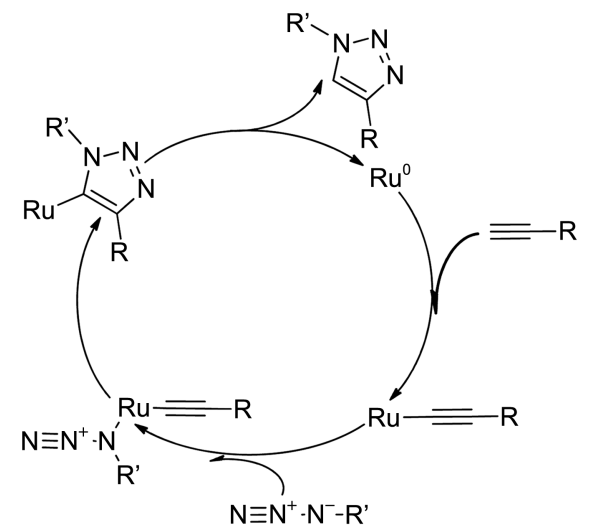

Scheme 1. Proposed mechanism for $\mathrm{Ru}^{0}$ catalyzed click reactions.

$4.45(\mathrm{~m}, 2 \mathrm{H})$ presence of $-\mathrm{CH}_{2}-\mathrm{N}-{ }^{13} \mathrm{C}-\mathrm{NMR}$ of compounds $\mathbf{1 ,} \mathbf{2}$ and $\mathbf{3}$ peaks at $\delta 121.29, \delta 122.31$ and $\delta 122.29$ clearly indicates 1,4-disubstituted-1H-1,2,3-triazole, which is uncommon reaction product using regular Ru catalysts. ${ }^{33}$ The proposed mechanism of the $\mathrm{Ru}^{0} \mathrm{NPs}$ catalyzed click reactions was shown in Scheme 1.

Tri-triazole compounds were synthesized by choosing 2,4,6-tris(prop-2-ynyloxy)-1,3,5-triazine (alkyne) and 1azidodecane and benzyl azide (azides) which are catalyzed by $\mathrm{Ru}^{0} \mathrm{NPs}$. The compound $\mathbf{4}$ shows the characteristic peak at $\delta 7.81(\mathrm{~s}, 3 \mathrm{H})$ indicates the presence of three triazole rings, and in ${ }^{13} \mathrm{C}-\mathrm{NMR}$ triazine ring carbons were detected at $\delta 171.57$ and triazole ring carbons at $\delta 137.93$ and 123.59. The transformations may be particularly applicable for drug discovery, not just because of its reliability as a linking reaction, but also because of the favorable physicochemical properties of triazoles. Indeed, as-synthesized $\mathrm{Ru}^{0} \mathrm{NPs}$ have

Table 1. $\mathrm{Ru}^{0} \mathrm{NPs}$ catalyzed cycloadditions of azides and alkynes

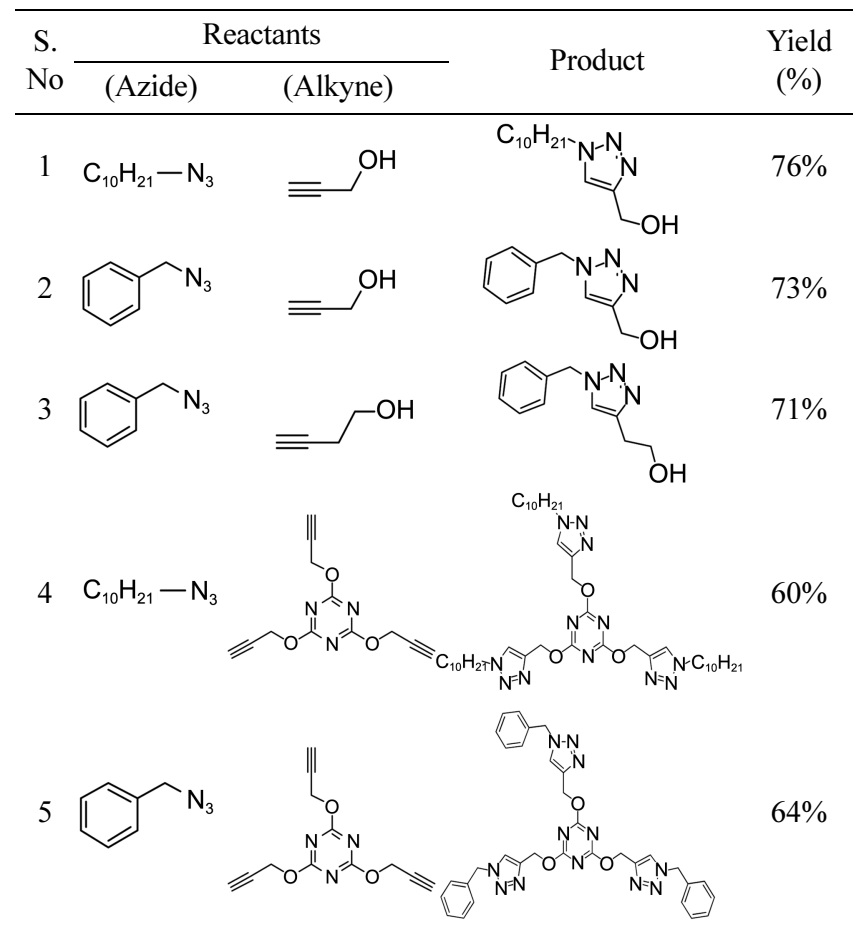


to be efficient and selective catalysts for azide-alkyne reactions.

The recyclability of the catalyst was performed for $\mathbf{1}$ and $\mathbf{2}$ azide-alkyne reactions. It has been obtained $97 \%$ of the reaction products after three cycles of the reactions and did not show significant change in the morphology of the $\mathrm{Ru}^{0}$ catalyst nanoparticles, which suggests the repetitive catalytic performance. The synthesized $\mathrm{Ru}^{0}$ nanocatalysts also show the reaction selectivity of azide-alkyne reactions which can be tuned in favor of target products depending on the reaction conditions. Finally, synthesis and catalytic application of $\mathrm{Ru}^{0}$ nanocatalysts are promising, and also obtained good recovery and recycling results.

\section{Conclusions}

Metal nanoparticles are of practical interest due to their unique physical properties, chemical reactivity, and potential applications in catalysis. The present chemical co-precipitation method was simple and easy way to synthesize $\mathrm{Ru}^{0}$ NPs (ranges from 10-20 nm) which can vary by changing the operational parameters (i.e., $\mathrm{pH}$ of the medium and type and concentration of the surfactant). As-synthesized $\mathrm{Ru}^{0}$ nanocatalyts are used for the azide-alkyne cycloaddition reactions and the reactions proceeded smoothly to form the corresponding products with good yields. The preliminary results of recycling are good for the recovery of these $\mathrm{Ru}^{0}$ nanocatalysts.

Acknowledgments. This work was supported by the Basic Science Research Program (NRF 2011-0010155) and the Priority Research Centers Program (NRF 2010-0029634) through the National Research Foundation of Korea (NRF) funded by the Ministry of Education, Science and Technology.

\section{References}

1. Tang, Z.; Kotov, N. A. Adv. Mater. 2005, 17, 951.

2. Daniel, M. C.; Astruc, D. Chem. Rev. 2003, 104, 293.

3. Astruc, D.; Lu, F.; Aranzaes, J. R. Angew. Chem. Int. Ed. 2005, 44, 7852.

4. Yan, N.; Xiao, C.; Kou, Y. Coord. Chem. Rev. 2010, 254, 1179.

5. Kumar, A. P.; Kumar, B. P.; Kumar, A. B. V. K.; Huy, B. T.; Lee,
Y. I. Appl. Surf. Sci. 2013, 265, 500.

6. Kirchhoff, M. M. Resour. Conserv. Recy. 2005, 44, 237.

7. Naota, T.; Takaya, H.; Murahashi, S. I. Chem. Rev. 1998, 98 , 2599.

8. Mallat, T.; Baiker, A. Chem. Rev. 2004, 104, 3037.

9. Olivier, C.; Costuas, K.; Choua, S.; Maurel, V.; Turek, P.; Saillard, J. Y.; Touchard, D.; Rigaut, S. J. Am. Chem. Soc. 2010, 132, 5638.

10. Chang, K. H.; Hu, C. C. Electrochem. Solid St. 2004, 7, A466.

11. Neupane, S.; Kaganas, G.; Valenzuela, R.; Kumari, L.; Wang, X. W.; Li, W. Z. J. Mater. Sci. 2011, 46, 4803.

12. Antonetti, C.; Oubenali, M.; Raspolli Galletti, A. M.; Serp, P.; Vannucci, G. Appl. Catal. A 2012, 421-422, 99.

13. Guerrero, M.; Roucoux, A.; Denicourt-Nowicki, A.; Bricout, H.; Monflier, E.; Collière, V.; Fajerwerg, K.; Philippot, K. Catal. Today 2012, 183, 34.

14. Gao, S.; Zhang, J.; Zhu, Y. F.; Che, C. M. New J. Chem. 2000, 24 , 739.

15. Dikhtiarenko, A.; Khainakov, S. A.; García, J. R.; Gimeno, J.; de Pedro, I.; Fernández, J. R.; Blanco, J. A. J. Alloys Compd. 2012, 536, S437.

16. Das, P.; Aggarwal, N.; Guha, N. R. Tetrahedron Lett. 2013, 54, 2924.

17. Cao, N.; Luo, W.; Cheng, G. Z. Int. J. Hydrogen Energ. 2013, 38, 11964.

18. Mishra, D. K.; Dabbawala, A. A.; Hwang, J. S. Catal. Commun. 2013, 41, 52 .

19. Moses, J. E.; Moorhouse, A. D. Chem. Soc. Rev. 2007, 36, 1249.

20. Kolb, H. C.; Sharpless, K. B. Drug Discov. Today 2003, 8, 1128.

21. Tron, G. C.; Pirali, T.; Billington, R. A.; Canonico, P. L.; Sorba, G.; Genazzani, A. A. Med. Res. Rev. 2008, 28, 278.

22. Paria, S.; Khilar, K. C. Adv. Colloid Interface Sci. 2004, 110, 75.

23. Patakfalvi, R.; Papp, S.; Dékány, I. J. Nanopart. Res. 2007, 9, 353.

24. Thirumurugan, P.; Matosiuk, D.; Jozwiak, K. Chem. Rev. 2013, $113,4905$.

25. Hein, C.; Liu, X. M.; Wang, D. Pharm. Res. 2008, 25, 2216.

26. Rostovtsev, V. V.; Green, L. G.; Fokin, V. V.; Sharpless, K. B. Angew. Chem. Int. Ed. 2002, 41, 2596.

27. Tornøe, C. W.; Christensen, C.; Meldal, M. J. Org. Chem. 2002, 67, 3057.

28. Breinbauer, R.; Köhn, M. ChemBioChem 2003, 4, 1147.

29. Lutz, J. F. Angew. Chem. Int. Ed. 2007, 46, 1018.

30. Zhang, L.; Chen, X.; Xue, P.; Sun, H. H. Y.; Williams, I. D.; Sharpless, K. B.; Fokin, V. V.; Jia, G. J. Am. Chem. Soc. 2005, $127,15998$.

31. Rasmussen, L. K.; Boren, B. C.; Fokin, V. V. Org. Lett. 2007, 9, 5337.

32. Boren, B. C.; Narayan, S.; Rasmussen, L. K.; Zhang, L.; Zhao, H.; Lin, Z.; Jia, G.; Fokin, V. V. J. Am. Chem. Soc. 2008, 130, 8923.

33. Zhang, L.; Chen, X. G.; Xue, P.; Sun, H. H. Y.; Williams, I. D.; Sharpless, K. B. J. Am. Chem. Soc. 2005, 127, 15998. 